\title{
MicroRNAs: Panacea or Pandora's box?
}

\author{
Paul Kurlansky, MD
}

See related article on pages 398-406.

Paraplegia is a devastating complication of aortic surgery. Depending on the specific anatomic parameters and techniques of operation, incidence has been reported to vary from $0 \%$ to $32 \%$, with most recent averages still exceeding $5 \%$. ${ }^{1}$ The fundamental problem is one of imbalance between oxygen supply and demand as a result of aortic clamping. Numerous strategies have been used to ameliorate this injury, including distal aortic perfusion, maintenance of mean systolic arterial pressure, cerebrospinal fluid drainage, hypothermia, epidural cooling, selective spinal cord perfusion, sequential aortic crossclamping, reimplantation of intercostal arteries, identification and preservation of the artery of Adamkiewicz, and adjunctive pharmacologic therapies (steroids, mannitol, barbiturates, etc), as recently outlined by Takayama and Borger ${ }^{2}$ in a recent edition of the Journal. The fact that thoracic endovascular aneurysm repair carries the same risk of paraplegia as open procedures supports the observation that spinal cord ischemia is primarily a matter of collateral blood flow and ischemic tolerance, rather than assisted circulation and selective intercostal reattachment, supporting the relative importance of cerebrospinal fluid drainage and maintenance of perfusion pressure relative to other techniques. ${ }^{3}$ Strategies that might improve spinal cord tolerance for ischemia or interfere with the mechanisms of ischemiareperfusion injury therefore provide a promising and important area for further investigation.

First discovered more than 2 decades ago, microRNAs (miRNAs) are small, noncoding RNA molecules containing approximately 22 nucleotides that function in the posttranscriptional regulation of gene expression through base pairing with complementary sequences within mRNA molecules and silencing gene expression by cleavage, destabilization, or interference with messenger RNA (mRNA) translation. ${ }^{4,5}$ Animal miRNAs recognize their target mRNA with as few as 6 to 8 nucleotides (the seed region), and this relative lack of specificity enables a

\footnotetext{
From the Department of Surgery, Columbia University, New York, NY

Disclosures: Author has nothing to disclose with regard to commercial support.

Received for publication March 27, 2015; accepted for publication March 30, 2015; available ahead of print May 6, 2015.

Address for reprints: Paul Kurlansky, MD, Department of Surgery, Columbia University, Black Building 210, 650 W 168th St, New York, NY 10032 (E-mail: pk2245@cumc.columbia.edu).

J Thorac Cardiovasc Surg 2015;150:407-8

0022-5223/\$36.00

Copyright (c) 2015 by The American Association for Thoracic Surgery http://dx.doi.org/10.1016/j.jtcvs.2015.03.061
}

given miRNA to have multiple discrete mRNA targets, fostering regulation of entire physiologic processes rather than specific proteins. A given miRNA may have hundreds of different mRNA targets, and a given target might be regulated by multiple miRNAs. ${ }^{6}$ Manipulation of miRNA expression therefore has the theoretic potential to control entire physiologic processes while simultaneously risking triggering multiple unanticipated pleiotropic effects. Much of the progress in miRNA research has been made with the use of antisense oligonucleotides (antagomirs) that target specific miRNAs and that can be chemically modified and bound to carrier molecules to improve hybridization affinity, resist degradation, and promote tissue uptake.

It is just this approach that is reported by $\mathrm{He}$ and colleagues $^{8}$ in this issue of the Journal. In a rat model of aortic clamping-induced spinal cord ischemia, they have convincingly demonstrated that the previous introduction of a lentivirus vector containing an oligonucleotide that specifically targets miRNA 320 improved hind limb motor function and increased motor neuron survival. They further demonstrated that introduction of this antagomir to miRNA 320 specifically reduced miRNA 320 expression and upregulated the expression of phosphorylated heat shock protein 20 (pHSP20). MicroRNA 320 was selected because of previous evidence implicating inhibition of this nucleotide in cerebral ischemic neuroprotection, ${ }^{9}$ whereas pHSP20 has been shown to be the target of the miRNA 320 regulation of cardiac ischemia-reperfusion injury. ${ }^{10}$

Should we now start performing preoperative intrathecal injection of lentivirus-laden oligonucleotides for all our thoracoabdominal aortic reconstructions? Not just yet. Even assuming that one were to construct an effective and specific antagomir to miRNA 320 that did not require the clinically unacceptable lentivirus vector and was biochemically active after intravenous injection (which has been accomplished for numerous other miRNA-inhibiting oligonucleotides), the aggregate physiologic impact at this time is unpredictable. By mapping miRNA path to gauge the impact of miRNA 320a modulation, Sepramaniam revealed approximately 145 pathways being affected, with as many as 1500 target genes (Figure 1). ${ }^{9}$ Whether pHSP20 is the critical mediator of spinal neuroprotection in the study of $\mathrm{He}$ and colleagues, ${ }^{8}$ a helpful participant, or merely a physiologic bystander is not addressed by this report. What might have proved helpful would have been investigation of the impact of pHSP20 inhibition (either through a specific chemical inhibitor or conversion to a mouse model with specific genetic knockout of pHSP20 


\section{Possible pathways/genes affected by miR-320a modulation.}

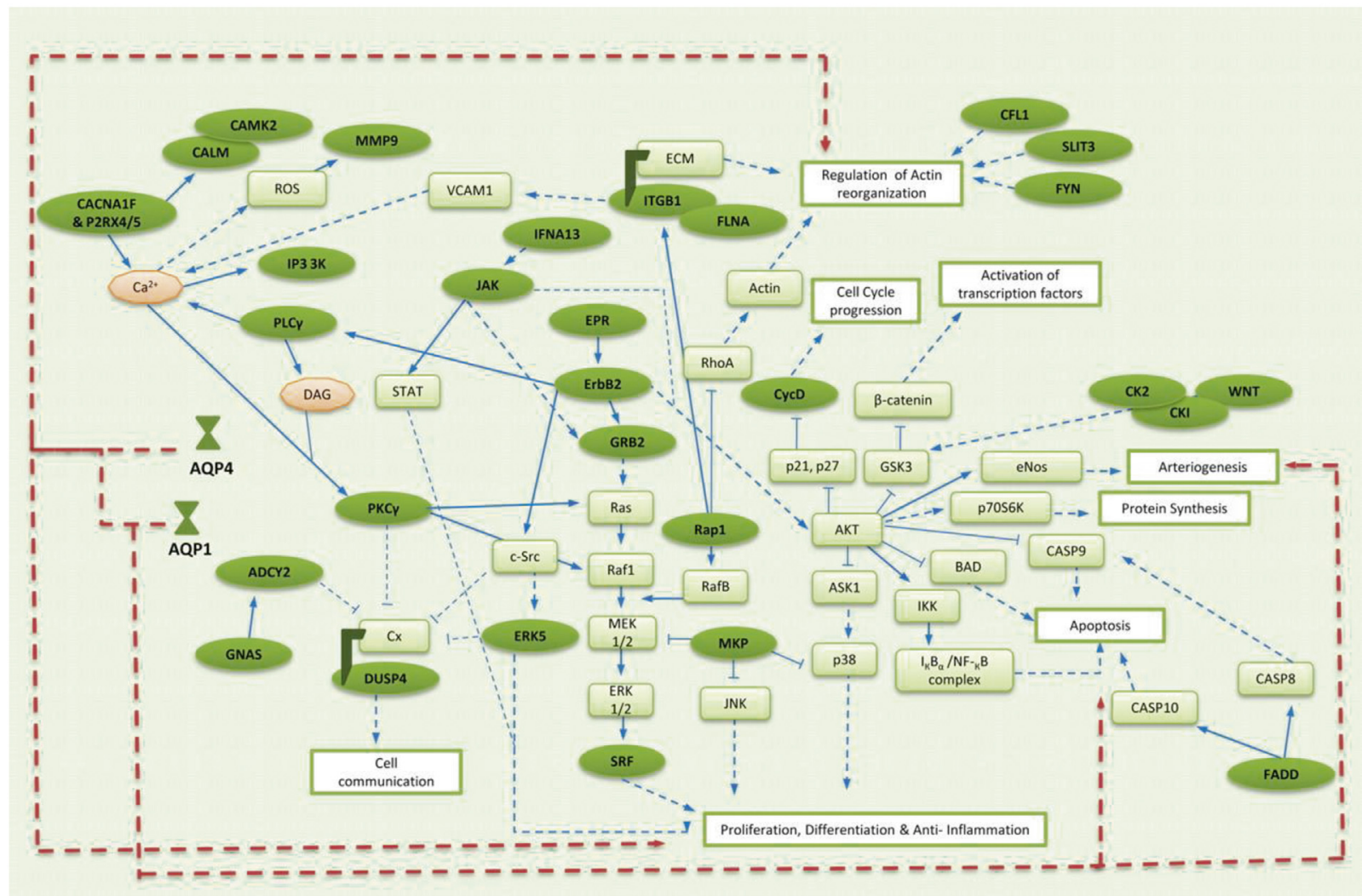

Sugunavathi Sepramaniam et al. J. Biol. Chem. 2010;285:29223-29230

FIGURE 1. Possible pathways and genes affected by microRNA 320a modulation. Compilation of possible genes affected by microRNA 320a modulation was adapted from the KEGG Pathway Database. Green ovals represent targets of microRNA 320a; green rectangles represent other genes in the pathway; pink ovals represent secondary messengers; blue right arrows represent direct interaction; dashed blue right arrows represent indirect interaction; and broken red right arrows represent aquaporin interaction. For a complete description of all terms used in the figure, see Figure 5 in Sepramaniam and colleagues. ${ }^{9}$ Reprinted with permission. ${ }^{9}$ ㄷ 2010 The American Society for Biochemistry and Molecular Biology.

expression) on the results of miRNA 320 inhibition. Such information would be useful not only for a clearer elucidation of the molecular mechanism of neuroprotection in this model but also for direction in the development of more targeted therapies. As is so often the case in molecular genetic investigation, He and colleagues ${ }^{8}$ may well have uncovered more questions than answers; however, they have clearly helped to focus our attention on a potentially productive path toward resolution of an unresolved and clinically compelling challenge.

\section{References}

1. Panthee N, Ono M. Spinal cord injury following thoracic and thoracoabdominal aortic repairs. Asian Cardiovasc Thorac Ann. 2015;23:235-46.

2. Takayama H, Borger M. Preventing spinal cord injury during thoracic aortic surgery: simpler than we thought? J Thorac Cardiovasc Surg. 2015;149:366-8.
3. Acher C, Wynn M. Paraplegia after thoracoabdominal aortic surgery: not just assisted circulation, hypothermic arrest, clamp and sew, or TEVAR. Ann Cardiothorac Surg. 2012;1:365-72.

4. Ambros V. The functions of animal microRNAs. Nature. 2004;431:350-5.

5. Bartel DP. MicroRNAs: genomics, biogenesis, mechanism, and function. Cell. 2004;116:281-97.

6. Krek A, Grün D, Poy MN, Wolf R, Rosenberg L, Epstein EJ, et al. Combinatorial microRNA target predictions. Nat Genet. 2005;37:495-500.

7. Esau CC. Inhibition of microRNA with antisense oligonucleotides. Methods. 2008;44:55-60.

8. He F, Shi E, Yan L, Li J, Jiang X. Inhibition of microRNA 320 attenuates neurologic injuries after spinal cord ischemia. J Thorac Cardiovasc Surg. 2015; 150:398-406.

9. Sepramaniam S, Armugam A, Lim KY, Karolin DS, Swaminathan P, Tan JR, et al. MicroRNA 320a functions as a novel endogenous modulator of aquaporins 1 and 4 as well as a potential therapeutic target in cerebral ischemia. J Biol Chem. 2010;285:29223-30.

10. Ren XP, Wu J, Wang X, Sartor MA, Qian J, Jones K, et al. MicroRNA-320 is involved in the regulation of cardiac ischemia/reperfusion injury by targeting heat-shock protein 20. Circulation. 2009;119:2357-66. 